\title{
SACRU VS. PROFAN ÎN APELATIVELE NECONVENȚIONALE ALE POLITICIENILOR ROMÂNI
}

\author{
Alexandra sorina Iliescu \\ Universitatea Tehnică din Cluj-Napoca, \\ Centrul Universitar Nord Baia Mare, România
}

\begin{abstract}
Sacred vs. profane in nicknames of Romanian politicians
Abstract: The field of politics is fertile ground for linguistic creativity, a phenomenon determined in particular by the changes made at the level of a state's governing structures. Various entities - mainly from the mass media - react against politicians' behavior, decisions and language, by giving them nicknames which contain terms from the spheres of the profane and the sacred. The terms from the semantic field of the sacred employed in "naming" politicians increase the degree of mockery of nicknames (the limits of irony are often transgressed and replaced with sarcasm). Our approach will focus on identifying the linguistic motivation of the sacred or profane content of nicknames given to politicians, as well as the social and contextual factors that triggered their birth. At the same time, throughout the investigation, we will analyze the etymology and semantic content of the selected terms. The theoretical perspective proposed is interdisciplinary, promoted by functional linguistics, pragmatics, stylistics and anthroponymy.

Keywords: sacred vs. profane, unconventional anthroponyms, lexical innovations, irony.
\end{abstract}

\section{Preliminarii}

\subsection{Introducere}

Domeniul politic se dovedește a fi un teren fertil al creativității lingvistice, proces generat, în principal, de răsturnările de situație petrecute pe scena publică cu diverse ocazii. Factorul declanșator al inovației îl reprezintă comportamentul social și lingvistic inadecvat al politicienilor în spațiul public, prilej de aplicare a unor sancțiuni de către alegători, și, în special, de către reprezentanții mass-mediei. Cel mai frecvent utilizate sancțiuni constau în atribuirea de apelative neconvenționale cu un conținut și cu forme specifice, conotate ironic. „Nicknames have become means of attack, picked by belligerent interlocutors from the arsenal at hand. They are prolonged-release antidotes used to destroy opponents and their effect is visible in the long run, as nicknames become part of users' collective memory. When this happens, speakers associate a nicknamed individual with the verbal tag considered emblematic of the nickname bearer" (Felecan D., Felecan O. 2016: 191) 
Una dintre structurile prin care locutorul își probează competența expresivă este aceea care include, în sfera sa semantică, sensuri aparținând domeniului sacru. Utilizarea unor astfel de structuri este un mecanism eficient de poreclire a politicienilor, un instrument de persiflare și de accentuare a sarcasmului, în vederea sporirii gradului de ridiculizare a celor vizați ${ }^{1}$.

\subsection{Obiect și metode de lucru}

În prezentul studiu, ne-am propus analiza unor apelative neconvenționale atribuite politicienilor români, porecle având în componență termeni din sfera religiosului. Corpusul cuprinde material lingvistic din presa on-line (de tip pamflet) și de pe blog-uri. Dintre acestea, am selecționat următoarele formule antroponimice: Sfântul Becali Milostivitorul, Mucenicul Victor, Sfântul Ponta, Pontificatorul Victor Viorelianus Pontifficacatu', Maica Elena Udrea, Maica Udrea, (des)făcătoarea de sistem și o unitate antroponimică: Pontificatorul, care desemnează anumiți actori politici autohtoni, „jucători” în diverse contexte situaționale ilustrative pentru evoluția evenimentelor politice românești.

Vom cerceta proveniența și vom analiza conținutul semantic al termenilor propuși, din perspectivă sociolingvistică și pragmastilistică.

\subsection{Considerații teoretice}

Actul de numire neoficială2 reprezintă o manifestare creativă a vorbitorului, care are loc la nivelul limbajului individual ${ }^{3}$, prilejuită de situația concretă de comunicare. Apelativul neconvențional „desemnează un singur obiect într-o situație determinată” (Bally, apud Coșeriu 2004: 270). Născute în sfera politicului, aceste apelative sunt condiționate contextual - și datorate faptului că politicienii au un comportament considerat nepotrivit de către societate. Astfel, deciziile adoptate de către reprezentanții puterii în stat (legi propuse și promulgate, tăieri salariale, fapte ilegale săvârșite de politicieni sau de aparținătorii lor) declanșează reacții de sancționare a respectivului comportament, prin aplicarea mecanismului de poreclire, mult mai expresiv decât utilizarea, în relatarea evenimentelor, a numelor oficiale ale actorilor politici, considerate nereprezentative, „insuficiente sau nepotrivite” (Felecan 2014: 36), pentru atmosfera creată de „cei numiți”.

1 „Critical eye and irony are part of human nature, and nicknaming, which does not imply recording a name in official documents, is the product of a fuzzy, imprecise, unidentifiable naming identity (vox populi), able to capture a nicknamed person's vulnerable point (especially a physical or mental flaw)" (Felecan O. 2016: 66).

2 Ionescu Pérez (2007: 219-222) realizează distincția între oficial și neoficial, din punctul de vedere al referentului unităților constitutive, al oficialității și al perspectivei producerii formulei antroponimice.

3 Pentru clasificarea nivelurilor limbajului, competențele lingvistice și conținuturile acestora, vezi Coșeriu 1994: 135-136; „Desemnarea corespunde nivelului general al limbajului, semnificația (în această accepțiune) limbii concrete respective, iar sensul nivelului textului” (Coșeriu 2009: 117-122). 
Termenii supuși, mai jos, analizei, fac parte din categoria onomastică a porecle$l o r^{4}$, unele dintre acestea căpătând statutul de antroponime clișeizate (Stroia 2015: 351362), în virtutea recurenței uzului lor.

Porecla reprezintă un instrument atât ofensiv, cât și defensiv, întrebuințările acesteia având funcțiile ( $c f$. Stroia 2015: 355-360) de:

- persiflare - persoana poreclită este caricaturizată ${ }^{5}$, histrionizată, faptele sale sunt luate în derâdere;

- manipulare - virulența cu care jurnaliștii sancționează personajele politice prin poreclire triază taberele politice adversare (în subsidiar, intenţia etichetării este de a determina reacții previzibile ale electoratului; denigrând un prim-ministru prin poreclire, notorietatea acestuia și a partidului din care face parte scade considerabil, obținându-se, astfel, efectul scontat - crearea unei imagini denaturate, astfel încât populația să susțină pe reprezentantul unei anumite „culori” politice);

- apărare - produsul actului de poreclire este resimțit cu o intensitate redusă atunci când se naște ca o reacție la atacurile lansate de adversarii politici.

În virtutea încadrării în clasa poreclelor, apelativele puse în discuție în paginile de față prezintă următoarele trăsături ${ }^{6}$ :

- au un accentuat caracter afectiv, - încărcătura semantică este indusă de antipatia față de politicianul poreclit, de dorința de a-i ataca și păta imaginea publică;

- speculează punctul vulnerabil al celui poreclit - comportamentul politic al indivizilor în calitate de decidenți nu concordă cu așteptările membrilor societății;

- sunt utilizate într-un cerc mai restrâns de persoane - frecvența uzului poreclelor cu trimitere la sfera religiosului este mai redusă decât a celor cu conotații laice / profane;

- mobilitate - sunt create necontenit și generate de evenimente politice specifice;

- intră în corelație cu alți reprezentanți ai aceleiași clase - aceluiași individ îi sunt atribuite mai multe porecle, în funcție de factorul declanșator al actului numirii: defectele sau faptele săvârșite de persoanele în cauză care se doresc a fi sancționate.

\footnotetext{
4 Conform ELR (s.v.), poreclele:

- reprezintă o categorie a supranumelor;

- sunt denumiri ocazionale, al căror conținut afectiv determină o clasificare în forme apreciative sau peiorative;

- cele mai multe sunt calificative, caracterizatoare;

- rezultatele aplicării lor au la bază ironia, umorul, simțul critic;

- la baza motivației stau întâmplări mai mult sau mai puțin cunoscute, ticuri verbale, expresii folosite mai des, defecte de rostire etc.;

- sunt personale, intime.

„Porecla este rezultatul procesului de convertire a numelor oficiale (de atribuire a unui nume ulterior celui primit de subiect prin actul de botez), funcționând ca substitut al numelui oficial al individului" (Felecan 2014: 35).

5 Porecla reprezintă „unul dintre instrumentele schematizării caricaturale” (ChelaruMurăruș 2010: 176).

6 În acord cu Felecan 2010: 81-120 și Felecan 2014: 34-38.
} 


\section{Apelative neconvenționale având în componență termeni din sfera religiosului, atribuite politicienilor români}

Acest „surogat nominal neoficial” (Felecan 2014: 36), numit „poreclă” este rezultatul „unei atitudini volitive puternic marcate subiectiv” ((Felecan 2014: 65), exprimând dorința de a pedepsi faptele politicienilor care contravin așteptărilor electoratului.

Sensul apelativelor neconvenționale, cum sunt cele discutate mai jos, rezultă doar din întrebuințarea lor concretă, iar decriptarea corectă a semnificației lor se realizează numai cunoscând contextul care a determinat nașterea respectivelor porecle. Astfel, pentru ca interlocutorul să observe ironia din spatele unor porecle ca Sfântul Ponta sau Mucenicul Victor ${ }^{7}$, este necesar ca acesta să fie familiarizat cu contextul în care ele au apărut - motivul care a determinat criticarea comportamentului celui poreclit, implicit, poreclirea și atacul la persoană de către adversarii politici. În cazul în care cititorul se situează în afara contextului, sensul acestor apelative poate fi perceput în mod eronat: intenţia locutorului de a denigra politicienii poate fi confundată cu dorința de a le evidenția latura pozitivă a comportamentului, întrucât termenii religioși aflați în componența respectivelor apelative le conferă acestora (la prima vedere) un sens pozitiv ${ }^{8}$.

Includerea unui element $\mathrm{cu}$ conotație „sacră” în formula antroponimică neconvențională, de tipul celei descrise mai sus, sporește gradul de ridiculizare a celui numit. Procesul numirii este bivalent: individul este scos dintr-o clasă - cea a politicienilor, în general, iar ulterior încadrat într-o altă clasă, cu efectiv mai restrâns - a celor care au căpătat o etichetă similară (de „sfinți”) în urma comportamentului exercitat.

Mecanismul de construcție a poreclelor care conțin termeni din sfera sacrului ${ }^{9}$ reprezintă un proces de desacralizare ${ }^{10}$, de desemantizare a termenilor religioși. Prin golirea de sens ${ }^{11}$ a respectivilor termeni, se ironizează faptele politicienilor, care sunt discreditați în fața populației. Prin asocierea cu numele de botez sau de familie ale politicienilor, termenii religioși își pierd încărcătura sacră, integrându-se în profan. Termenii aparținând câmpului semantic al sacrului ${ }^{12}$ - de tipul sfânt, mucenic, pontificare nu mai au nimic a face cu divinitatea, cucernicia și desăvârșirea, devenind instrumente

\footnotetext{
7 Referentul este fostul prim-ministru al României, Victor Ponta.

8 Din perspectiva coșeriană, „actul de numire implică o intuiție și o expresie ale individului care numește și o percepere și o imagine ale receptorului” (Felecan 2014: 74).

9 Apelativele supuse investigării au în componență termeni din Biblie.

10 Sacrul și profanul sunt „două modalități de a fi în Lume, două situații existențiale asumate de om de-a lungul istoriei sale [...], determinate de diferitele poziții pe care omul le-a cucerit în Cosmos" (Eliade 2007: 15).

11 „Niciun semn lingvistic nu are exact aceeași formă și aceeaşi valoare (semnificat) la toți indivizii care îl utilizează și în toate momentele când este folosit [...] Fiind întotdeauna expresie a unei intuiții inedite și unice, actul lingvistic este un act de creație, act singular, care nu reproduce exact niciun act lingvistic anterior" (Coșeriu 1999: 25).

12 Stoian 1994: 243 definește sacrul ca având „caracter divin, care ține de religie”.
} 
de batjocorire a politicienilor. Opoziția dintre cei doi semnificați - „ceea ce percepe receptorul în momentul actualizării numelui unui politician” (Ponta, Udrea) ${ }^{13}$ și sensul prototipic al termenului din câmpul semantic al sacrului („sfânt”, "mucenic”) produce efecte de minimalizare și de ridiculizare a autorității politicienilor porecliți. Golirea de sens sacru a termenilor conduce, în plan lingvistic, la încălcarea concordanței ${ }^{14}$ dintre forma expresiei și conținutul său, la incongruență generatoare de umor sarcastic, în sfera universurilor de discurs ${ }^{15}$. Politicienii reprezintă autoritatea în stat, iar divinitatea este imaginea autorității religioase supreme. Mecanismul poreclirii funcționează, în acest caz, prin alăturarea numelor de botez sau de familie din sfera profană și a celor religioase $^{16}$, rezultând o realitate distorsionată (elementul comun - în cazul de faţă, cel al autorității - fiind învestit cu o altă semnificație $\left.{ }^{17}\right)$. De fapt, inserarea lexemelor aparținând câmpului semantic al sacrului în construcția poreclelor conduce la o simulare a recunoașterii autorității politicienilor în cauză. Prin poreclire, cel care numește neagă autoritatea celui numit, îl ironizează ${ }^{18}$ și îi reduce imaginea la minimum.

\subsection{Aspecte lingvistice}

Termenii folosiți pentru a porecli personalitățile din politica românească, se încadrează în următoarele categorii:

- sub aspect gramatical, în clasa numelor proprii ${ }^{19}$ (Sfântul Becali Milostivitorul, Mucenicul Victor, Sfântul Ponta, Pontificatorul Victor Viorelianus Pontifficacatu');

- sub aspect lexical, unele dintre acestea sunt deantroponime latinizate ${ }^{20}$ (Pontificatorul Victor Viorelianus Pontifficacatu'), formule construite prin paralelism

13 Politicienii numiți au fost reprezentanții puterii în stat (Victor Ponta - fost prim-ministru, Elena Udrea fost ministru al turismului și candidat la președinția României); în consecință, actualizarea numelor acestora înseamnă și recunoașterea autorității lor.

14 „Semnificatul este conținutul unui semn sau al unei expresii dat într-o anumită limbă și exclusiv prin intermediul limbii înseși” (Coșeriu 2000: 246).

15 Măgureanu (2008: 111) definește universul de discurs ca fiind „un ansamblu finit de propoziții folosite de către agentul discursiv în enunțarea / interpretarea / evaluarea enunțurilor produse în schimbul discursiv".

16 „Semnificația funcționează ca semnificant + semnificat, deci ca semn, și pentru sens, semnificatul literal al antroponimelor neconvenționale, intenția cu care acesta a fost creat / performat” (Felecan 2014: 74).

17 „Cel care interpretează enunțul ar trebui să remarce și să folosească în sprijinul său faptul că enunțul ironic trimite la o componentă particulară a universului de discurs - la o lume contrafactuală” (Negrea 2010: 95).

18 „Ironistul simulează că afirmă, că întreabă sau că susține ceva și, prin aceasta, exprimă o atitudine față de cei care ar face, ar întreba sau ar susține în această manieră sau față de acei oameni, acele acțiuni sau acele atitudini pe care simularea le angajează” (Currie 2006: 113).

19 „Numele proprii sunt lipsite de sens în afara actului denominativ de individualizare a unui anumit obiect. Relația temporară care se stabilește între numele propriu și obiectul denumit, dependentă de contextul situațional, creează semnificația numelui propriu, legată exclusiv de obiectul individualizat” (Manu Magda 2011: 507).

20 Clasă a apelativelor neconvenționale românești latinizate, care „combină, într-o formulă 
semantic (Sfântul Becali Milostivitorul, Mucenicul Victor, Sfântul Ponta, Sfântul Victor, Pontificatorul);

- sub aspect onomastic, aceștia sunt termeni care funcţionează în cadrul formulelor antroponimice ( $c f$. Ionescu Pérez 2007: 219-222).

\subsection{Aspecte pragmastilistice}

În plan stilistic, apelativele analizate, având ca punct de plecare numele unor politicieni români, sunt înzestrate cu sensuri evaluative, conotate ironic sau peiorativ, în funcție de starea sufletească a locutorului care le-a creat (v. Stoichițoiu Ichim 2011:25; Felecan 2014: 183).

Atribuirea apelativelor nume proprii oficiale reprezintă o modalitate comună, motivată, de identificare a referentului, numirea realizându-se cu intenția de a califica individual pe cel vizat, atribuindu-i „o calitate care îl caracterizează și îl specifică” (Charaudeau 1992: 663).

Numele neconvenționale în discuție, pe de altă parte, sunt constituite prin:

- „modificare semantică,

- procedee derivative și

- joc de cuvinte" (Zafiu 2010: 47).

Poreclele avute în vedere aparțin limbajului familiar-argotic, fiind utilizate în presă şi în mediul virtual de către autorii articolelor de tip pamflet și de către utilizatori ai internetului, având o frecvență mai redusă decât apelativele nume proprii care nu au în componență termeni din sfera lexicală a sacrului sau a numelor generice prin care sunt etichetați politicienii (cf. Felecan 2014: 132-136; Stroia 2015: 351-364).

\subsection{Antroponime în context}

În continuare, supunem analizei termenii selecționați din sfera discursului politico-publicistic actual: în perspectiva prezentată anterior.

Pontificatorul, Pontificatorul Victor Viorelianus Pontifficacatu', SfÂNTUl Ponta - porecle atribuite ex-prim ministrului român, Victor Ponta.

Pontificatorul - substantiv format prin derivare cu sufix nume de agent (a pontifica + suf. -tor), articulat cu articolul hotărât $-l$.

Prin analogie implicită (cu numele de familie al fostului prim-ministru al României, Victor Ponta), se realizează transferul semantic de la cuvântul inițial ${ }^{21}$ conotat pozitiv, cu trimitere la pontifex (capul Bisericii Catolice) la substantivul propriu Pontificatorul. Imaginea fostului prim-ministru este puternic atacată, funcția poreclei fiind de a critica felul în care Victor Ponta și-a exercitat autoritatea în cursul mandatului său - a luat decizii după propriile convingeri și nevoi, fără să țină seama de aşteptările și

complexă, antroponimul propriu-zis (preexistent) cu un apelativ antroponimizat" (Felecan 2014: 132-136).

${ }^{21}$ Pontificat - demnitate de papă; perioadă în care își exercită funcția un pontif (Stoian 1994: 215). 
nevoile poporului (tăieri de salarii și pensii, numirea în funcții a rudelor, reintroducerea taxei „de primă înmatriculare”). Totodată, porecla este încărcată de umor sarcastic - în viziunea locutorului, Pontificatorul a acaparat puterea și țara, încercând să își impună, în mod nedemocratic, propriul mod de guvernare.

(1) Ca orice marionetă ridicată pe poziție la care nu spera nici în visele adolescentine, odată văzut cu cuțitul în mână, Pontificatorul a început să creadă, ca şi Băse, că El este deținătorul adevărului absolut şi trasează sau schimbă direcții după bunul plac, indiferent de impactul pe care îl au asupra cetățenilor, indiferent dacă în felul acesta îşi contrazice propriile principii enunțate anterior (http://www.in-cuiul-catarii.info/).

Pontificatorul Victor Viorelianus Pontifficacatu' - deantroponim, are în componență termeni care reprezintă invenții lexicale latinizante ( $c f$. Felecan 2014: 134), și anume:

Pontificatorul - apelativ (onimizat), marcator al categoriei „socioprofesionale” în care este inclus cel numit;

Victor - numele de botez real al fostului prim-ministru;

Viorelianus - al doilea nume de botez real al politicianului, denaturat prin sufixare în manieră latinizantă -

derivare cu sufixul -an de la numele Viorel (al doilea nume de botez al lui Victor Ponta), la care s-a alipit sufixul latinesc -us, după modelul construcției numelor împăraților romani ${ }^{22}$. Sufixul și desinența care intră în componența numelui nou-format alcătuiesc cuvântul anus, făcându-se astfel legătura de sens cu ultimul termen al formulei, Pontifficacatu'.

Rezultă, din formula finală, că Victor Ponta este la fel de nefolositor precum materiile fecale. Construcția oximoronică a poreclei scoate în evidență virulența atacului la persoana fostului premier, formula făcând trimitere atât la forță și măreție (prin aluzia la împărații romani), cât și la dezagreabil, dezgustător, nefolositor (prin prezența cuvintelor din câmpul semantic al fecalelor);

Pontifficacatu' - termen a cărui grafie este motivată - silaba -ca este reduplicată, pentru obținerea voită a cacofoniei. Suprimarea articolului hotărât $-l$ din grafia cuvântului și înlocuirea acestuia cu apostrof amplifică intenția persiflantă a locutorului față de imaginea lui Victor Ponta și situează termenul în registrul familiar-argotic.

(2) Cică Pontificatorul Victor Viorelianus Pontifficacatu' a fost atât de multumit că a putut să bucure românii cu aceste carduri, încât a decis ca, de la 1 iunie 2015, să ofere bani românilor wireless! (http://cetin.ro/).

Sfântul Ponta - contextul care a determinat nașterea acestui apelativ a fost sărbătorirea zilei onomastice ${ }^{23}$ a lui Victor Ponta, când Mihai Fifor, membru USL, a pre-

\footnotetext{
22 Cf. Antonius, Aurelius, Iulius, Lucius etc.
}

23 Despre Sfântul Mucenic Victor se spune că a fost silit să renunțe la creștinism, prin supunerea la diverse forme de tortură fizică - sfărâmarea degetelor, otrăvire, tăierea venelor, jupuirea pielii și aruncarea în ulei clocotit. În cele din urmă, a fost decapitat la 11 noiembrie 160 (v. Bălan 
cizat că fostul premier „se ridică la condiția unui martir”. Formula antroponimică este construită din apelativul generic ${ }^{24}$ extras din sfera religiosului, sfântul, urmat de numele de familie al fostului prim-ministru. Sensul formulei este ironic, locutorul criticând, în acest mod, activitățile ilicite ale acestuia - fals în înscrisuri, complicitate la evaziune fiscală, spălare de bani, conflict de interese, furt intelectual, fapte incompatibile cu atributul de sfânt.

(3) [...]poate sfântul Ponta va da rapid o ordonanță de urgență, prin care Catedrala Mântuirii Neamului va trece în subordinea guvernului" (http://www.academiacatavencu. info).

Asocierea, prin poreclire, a imaginii lui Victor Ponta cu cea a Sfântului Mucenic Victor se bazează doar pe considerentul calității de sfânt, locutorul declarând că nu cunoaște istoricul martirului în cauză. În consecință, fostul prim-ministru este considerat un sfânt negativ, nefast, care, prin faptele sale, dăunează populației.

(4) Acum, eu nu știu cine a fost acest sfânt Victor, dar mă întreb în ce lume plagiatorul-şef al guvernului este un martir (http://www.academiacatavencu.info).

Mucenicul Victor - în același context, Victor Ponta a căpătat porecla de Mucenicul Victor, formulă antroponimică motivată de pătimirile imaginare care i se atribuie.

(5) Mucenicul Victor s-a luptat cu cine știe ce alt sfânt pentru o excursie la Ierusalim (http://www.academiacatavencu.info).

În ambele cazuri, conotația sacră, benefică a lexemelor sfânt și mucenic este anulată de referentul profan, cu trăsături de caracter negative (minciună, dezinteres, plagiat).

SfÂNtul Becali Milostivitorul - poreclă atribuită lui George Becali, aromân bogat din Pipera, intrat în politică cu intenții de parvenire socială.

Milostivitorul - termen format prin derivare cu sufixul nume de agent -tor de la verbul a se milostivi, inovație lexicală (termenul nu figurează în DEX sau DOOM 2 ), care evidențiază actele de caritate (milostenie) făcute de Gigi Becali (ajutor financiar acordat bisericilor, mănăstirilor și celor sinistrați în urma calamităților naturale); conform tiparului construcției hagionimelor care evidențiază darea de mână a celui numit, porecla conferită lui George Becali trebuia să conțină determinantul „cel milostiv”. Derivatul nume de agent milostivitorul conferă un caracter activ formulei antroponimice din care

Mihailovici 2003: 616). Pomenirea Sf. Mc. Victor se face la 11 noiembrie, conform calendarului ortodox (http://www.noutati-ortodoxe.ro/calendar-ortodox/).

24 „Antroponimul generic este rezultatul asocierii constante a unui nume propriu cu anumite valori culturale și contextuale care îi motivează semnificația generică” (Felecan 2014: 151). 
face parte, punând în evidență ostentaţia actelor caritabile făcute de George Becali - un făcător de milostenie, care, pe această cale, urmărește captarea atenției publicului, atragerea simpatiei acestuia, precum și augmentarea capitalului electoral.

(6) Sfântul Becali Milostivitorul se iubeşte cu Poporul (http://www.academiacatavencu. info/).

Structura formulei (7) este polifonică: în actul de poreclire, se identifică atât ironizarea lui George Becali, cât și a susținătorilor lui, toleranți ai faptelor ilegale săvârșite de cei care, ocazional, fac și acte de caritate.

(7) „Dacă Becali fură, măcar face şi fapte bune... nu zice nimeni că e sfânt... că nimeni nue perfect". Îl asigurăm pe autorul comentariului (doar o interfață a multor asemenea venite dinspre popor) că nu are dreptate: Becali chiar este sfânt şi aproape perfect; deşi a mai dat câte o muie, şi aia numai cu gura, calitățile sale evlavioase îl fac un candidat la sanctificare cu şanse mai mari şi decât cele ale lui Arsenie $e^{25}$. (http://www.academiacatavencu.info/)

Maica Elena Udrea, Maica Udrea, (Des) FăCĂTOAREa de Sistem - formule care o vizează pe Elena Udrea, ex-colaboratoarea președintelui Băsescu, ministru al turismului etc.

(8) „Să ne rugăm cu Maica Elena Udrea” (http://adevarul.ro).

Enunțul reprezintă o parte componentă a titlului unui articol de tip pamflet, titlu care include un fals îndemn ${ }^{26}$ la rugăciune pentru cititori.

Ironia la adresa femeii-politician rezultă din exploatarea sensului conotativ cu care a fost învestit termenul maica ${ }^{27}$, locutorul persiflând strategia electorală a Elenei Udrea - constând în apelul la cele sfinte ${ }^{28}$, cu scopul de a-și recâștiga credibilitatea în rândul votanților. În altă ordine de idei, este ironizată și decizia acesteia de a se înscrie la un program de masterat din cadrul Facultății de Teologie de la Universitatea BabeșBolyai din Cluj-Napoca.

Formula antroponimică, în discuție, este însoțită de apelativul generic preacucernica, acesta accentuând atitudinea ironică a locutorului - faptele Elenei Udrea, implicată

25 Se face referire la Părintele Arsenie Boca, cunoscut pentru previziunile sale, ajutorul acordat credincioșilor și opoziția sa față de regimul comunist.

26 Prin utilizarea verbului la modul conjunctiv, cu valoare imperativă să ne rugăm.

27 máică, maici s. f. 1. Mamă. $\bigotimes$ Termen afectiv cu care cineva se adresează copiilor sau unei persoane mai tinere. $\diamond$ Maica Domnului = Fecioara Maria, Născătoare de Dumnezeu 2. Călugăriță; termen cu care cineva se adresează unei călugărițe (Stoian 1994: 192).

28 În timpul campaniei electorale pentru alegerile Parlamentare din anul 2016, Elena Udrea a efectuat o serie de postări pe rețeaua de socializare Facebook în care vorbea despre iertare, credință, post și rugăciune. 
în scandaluri politice, acuzată și condamnată pentru comiterea de fapte ilicite ${ }^{29}$, sunt neconforme cu cele pe care ar trebui să le îndeplinească o „maică preacucernică”.

(9) Preacucernica maică Elena Udrea a ajuns la un nou level al campaniei electorale (http://www.bitpress.ro).

Maica Udrea, (des)făcătoarea de sistem - urmează tiparul denominativ al formulei antroponimice care desemnează persoanele ce operează cu magia neagră ${ }^{30}$ și trimite la o persoană care face și desface destinele poporului în funcție de legea bunului plac. Reprezintă titlul unui articol-pamflet, care sancționează un soi de diplomație politică situată în vecinătatea ipocriziei - în cazul de față, Elena Udrea a amânat sesiunea de live chat ${ }^{31}$ cu electoratul, întrucât intervalul orar s-a suprapus cu cel în care se desfășura slujba duminicală.

(10) Maica Udrea, (des)făcătoarea de sistem, face live chat (http://www.bitpress.ro).

\section{Concluzii}

În urma analizei apelativelor neconvenționale propuse, s-a constatat că:

- înțelegerea semnificației acestora impune plasarea cititorului în context: este necesară cunoașterea

contextului care a determinat atribuirea poreclei, precum și faptele politicienilor porecliți, în vederea decriptării corecte a sensului la nivel discursiv;

- mecanismul lor de construcție poate fi considerat un joc lingvistic ( $c f$. Felecan 2011: 568), în care termenii:

- sunt latinizați și transformați în apelative nume proprii;

- sunt incluși în formule antroponimice formate după un model preexistent, fiind „rezultat al creativității libere a locutorilor” (Felecan 2014: 143);

- acestea au funcție expresivă cu puternic impact emoțional asupra alocutorilor.

Apelativele neconvenționale care au în componență termeni din câmpul semantic al sacrului sunt mai rare, au o gamă restrânsă de utilizatori, fiind tipice pentru textele tip pamflet.

29 Elena Udrea are patru dosare de cercetare penală (Microsoft, Gala Bute, Hidroelectrica și BRD), în care este acuzată de săvârșirea infracțiunilor de: trafic de influență, spălare de bani, abuz în serviciu, luare de mită, instigare la abuz în serviciu, fals în declarații, obținere în mod ilegal a unui credit bancar de la BRD (https://www.stiridinlume.ro/).

30 Tămăduitoarea și clarvăzătoarea Silvia, Vindecătoarea-tămăduitoarea Elisabeta (http:// www.vrajitoare.eu/).

31 Elena Udrea obișnuia să organizeze discuții în direct pe rețeaua de socializare Facebook, în cadrul cărora aducea în discuție subiecte cu tematică religioasă. 


\section{Bibliografie}

Bălan-Mihailovici, A. 2003. Dicţionar onomastic creştin: repere etimologice şi martirologice. București: Minerva.

Bidu-Vrănceanu, A., C. Călăraşu, L. Ionescu-Ruxăndoiu, M. Mancaş, G. Pană Dindelegan. 2001. Dicționar de ştiințe ale limbii (DSL). Bucureşti: Nemira.

Charaudeau, P. 1992. Grammaire du sens et de l'epression. Paris: Hachette.

Chelaru-Murăruș, O. 2010. Nume, porecle, semnături ironice în paginile „Academiei Cațavencu”. În Limba română: Controverse, delimitări, noi ipoteze (II), Pragmatică și stilistică, Actele celui de-al 9-lea Colocviu al Catedrei de limba română (București 4-5 decembrie 2009), Rodica Zafiu, Adina Dragomirescu, Nicolae Alexandru (eds.), 175-184. București: Editura Universității din București.

Coșeriu, E. 1994. Lingvistică din perspectivă spațială și antropologică. Trei studii. Chișinău: Știința. Coșeriu, E. 1999. Introducere în lingvistică. Cluj-Napoca: Echinox.

Coșeriu, E. 2000. Lecții de lingvistică generală. Chișinău: Arc.

Coșeriu, E. 2009. Omul și limbajul său. Studii de filosofie a limbajului, teorie a limbii și lingvistică generală. Iași: Editura Universității „Alexandru Ioan Cuza”.

Currie, G. 2006. Why Irony is Pretence. În The Architecture of Imagination. New Essay on Pretence, Possibility, and Fiction, S. Nichols (coord), 111-133. New York: Oxford University Press.

Eliade, M. 2007. Sacrul și Profanul. București: Humanitas.

Felecan, D. 2011. Names within the Romanian Public Space: Formation Patterns and Communicative Functions. În Cultural Spaces and Archaic Background, The International Conference of Intercultural Studies and Comparativism „Cultural spaces and archaic foundations”, Baia Mare, 2010, D. Suiogan, Ș. Mariș, C. Dărăbuș (coord.), 558-574. Baia Mare: Ethnologica Publishing.

Felecan, D. 2014. Pragmatica numelui și a numirii neconvenționale: de la paradigme teoretice la practici discursive. Cluj-Napoca: Mega / Argonaut.

Felecan, D., O. Felecan. 2016. Nicknames of Romanian Politicians after 1989. Philologica Jassyensia 24 (2): 191-208. http://www.philologica-jassyensia.ro/upload/XII_2 FELECAN.pdf (accesat în septembrie 2017).

Felecan, N. 2010. Categoriile antroponimice: nume, supranume, poreclă. În Onomasticon. Studii despre nume și numire I, Oliviu Felecan (coord.), 81-120. Cluj-Napoca: Mega.

Felecan, O. 2016. A Psycholinguistic Approach to Nicknaming (With Reference to Nicknames Given by Students to Teachers). In 'Names and Their Environment'. Proceedings of the 25th International Congress of Onomastic Sciences, Glasgow, 25-29 August 2014, vol. 3, C. Hough, D. Izdebska (eds.), University of Glasgow, 65-81. http://www.icos2014.com/wp-content/ uploads/icos2014_vol_3.pdf (accesat în septembrie 2017).

Ionescu Pérez, P. C. 2007. Concepte, metodologie și terminologie în antroponimia romanică. În Limba română, limbă romanică. Omagiu acad. Marius Sala la împlinirea a 75 de ani, Sanda Reinheimer Rîpeanu, Ioana Vintilă Rădulescu (coord.), 215-230. București: Editura Academiei Române.

Manu Magda, M. 2011. Pragmatică și antroponimie (considerații teoretice referitoare la sistemul apelativelor în limba română). În Numele și numirea. Actele Conferinței Internaționale de Onomastică, ediția I, Interferențe multietnice în antroponimie, Baia Mare, 19-21 septembrie 2011, Oliviu Felecan (coord.), 503-513. Cluj-Napoca: Mega. 
Măgureanu, A. 2008. La structure dialogique du discours. București: Editura Universității din București.

Negrea, E. 2010. Pragmatica ironiei. Studiu asupra ironiei în presa scrisă românească. București: Tritonic.

Sala, M. (coord.). 2001. Enciclopedia limbii române. București: Univers Enciclopedic.

Stoian, I. M. 1994. Dicționar religios - termeni religioși, credințe populare și nume proprii. București: Garamond.

Stroia, A. R. 2015. Antroponime clișeizate în emisiunile de tip pamflet: între persiflare și manipulare. În Numele și numirea. Actele conferinței internaționale de onomastică, ediția a III-a, convențional / neconvențional în onomastică, Oliviu Felecan (coord.), 350-364. Cluj-Napoca: Mega.

Zafiu, R. 2010. 101 cuvinte argotice. București: Humanitas.

\section{Surse}

http://cetin.ro/

http://www.academiacatavencu.info

http://www.bitpress.ro

http://www.in-cuiul-catarii.info/

http://www.noutati-ortodoxe.ro/calendar-ortodox/

http://www.vrajitoare.eu/

https://www.stiridinlume.ro/ 